\title{
Playing cards on asthma management: A new interactive method for knowledge transfer to primary care physicians
}

\author{
Louis-Philippe Boulet MD FRCPC ${ }^{1}$, Francine Borduas $M D^{2}$, Jacques Bouchard MD², Johanne Blais $M D^{2}$, \\ Frederick E Hargreave MD FRCPC ${ }^{3}$, Michel Rouleau MD²
}

\begin{abstract}
L-P Boulet, F Borduas, J Bouchard, J Blais, FE Hargreave, M Rouleau. Playing cards on asthma management: A new interactive method for knowledge transfer to primary care physicians. Can Respir J 2007;14(8):480-484.
\end{abstract}

OBJECTIVES: To describe an interactive playing card workshop in the communication of asthma guidelines recommendations, and to assess the initial evaluation of this educational tool by family physicians.

DESIGN: Family physicians were invited to participate in the workshop by advertisements or personal contacts. Each physician completed a standardized questionnaire on his or her perception of the rules, content and properties of the card game.

SETTING: A university-based continuing medical education initiative.

PARTICIPANTS: Primary care physicians.

MAIN OUTCOME MEASURES: Physicians' evaluation of the rules, content and usefulness of the program.

RESULTS: The game allowed the communication of relevant asthmarelated content, as well as experimentation with a different learning format. It also stimulated interaction in a climate of friendly competition. Participating physicians considered the method to be an innovative tool that facilitated reflection, interaction and learning. It generated relevant discussions on how to apply guideline recommendations to current asthma care.

CONCLUSIONS: This new, interactive, educational intervention, integrating play and scientific components, was well received by participants. This method may be of value to help integrate current guidelines into current practice, thus facilitating knowledge transfer to caregivers.
Jeu de cartes interactif sur le traitement de l'asthme : Nouvelle méthode pour le transfert de connaissances aux médecins de famille

OBJECTIFS : Décrire un atelier portant sur un jeu de cartes interactif ayant pour but de faire connaître les recommandations et les lignes directrices sur l'asthme, et évaluer les premiers commentaires des médecins de famille au sujet de cet outil de formation.

PLAN : Des médecins de famille ont été invités à participer à cet atelier par voie de communiqués et d'invitations personnelles. Chaque médecin a répondu à un questionnaire standardisé sur sa perception des règles, du contenu et des propriétés du jeu de cartes.

CONTEXTE : Projet mis sur pied par un département de formation médicale continue universitaire.

PARTICIPANTS : Médecins de première ligne.

PRINCIPAUX PARAMÈTRES : Évaluation par les médecins des règles, du contenu et de l'utilité du programme.

RÉSULTATS : Le jeu a permis la transmission de connaissances pertinentes sur l'asthme et l'expérimentation d'un outil d'apprentissage différent. Il a aussi favorisé l'interaction dans un climat de compétition amicale. Les médecins participants ont jugé la méthode originale, propice à la réflexion, aux échanges et à l'apprentissage. Des discussions intéressantes en ont découlé sur les façons d'appliquer les lignes directrices aux soins actuels.

CONCLUSIONS : Cette nouvelle méthode de formation interactive, qui allie jeu et éléments scientifiques a été bien accueillie par les participants. Elle pourrait être utile pour l'intégration des directives actuelles dans la pratique et faciliter du même coup le transfert de connaissances aux professionnels de la santé.

Key Words: Asthma; Game-based learning; Knowledge implementation; Medical education

sthma is one of the most common chronic conditions, and Aits prevalence has been increasing over the past few decades (1). Unfortunately, asthma management is still suboptimal, and despite the production of numerous evidence-based guidelines, key recommendations of these national and international reference guides are often unknown to general practitioners or are not translated into current practice $(2,3)$. Various methods have been proposed to improve and update medical practice. Among the most effective methods are those that have a strong interactive component and that include specific educational interventions adapted to the physicians' needs, thus providing a means to integrate the information provided into day-to-day care (4-7). Game-based programs that integrate problem-based learning processes have been developed not only for patient education but also for continuing medical education (CME). Computer programs, quizzes and card games have been commonly used for student and patient education $(8,9)$. For CME, the most common format is computer programs. For example, a study by Mann et al (10) demonstrated the efficacy of using a computer game model as a tool for surgical education, simulating real-life clinical situations.

We describe a new game-based method of knowledge transfer in the form of a card playing session. This new card game uses both play and scientific components in communicating

${ }^{1}$ Institut universitaire de cardiologie et de pneumologie, Hôpital Laval; ${ }^{2}$ Bureau de formation médicale continue, Faculté de Médecine, Université Laval, Québec, Québec; ${ }^{3} \mathrm{McM}$ aster University, Hamilton, Ontario

Correspondence: Dr Louis-Philippe Boulet, Institut de cardiologie et de pneumologie de l'Université Laval, Hôpital Laval, 2725 Chemin Sainte-Foy,

Québec, Québec G1V 4G5. Telephone 418-656-4747, fax 418-656-4762, e-mail lpboulet@med.ulaval.ca 
asthma guidelines recommendations $(11,12)$. Another objective was to describe the initial evaluation of the game by a group of primary care physicians. To our knowledge, this is the first 'card game' method applied to knowledge transfer of assessment and treatment guidelines in primary care.

\section{PROGRAM DEVELOPMENT}

The program was developed following five consensus meetings of the authors to determine what the format of the card game should be and how it could include all the basic elements of the current Canadian asthma guidelines.

A list of the most frequently asked topics at previous asthma CME events was produced, and specific case scenarios and questions were developed for each theme that emerged from this list. A score for each case scenario card was also created. This program was conducted according to the code of ethics of the Conseil de l'éducation médicale continue du Québec.

\section{PARTICIPANTS AND METHODS}

Family physicians were invited to participate in the interactive playing card workshop by the Laval CME office and by advertisements or contacts at Quebec City (Quebec) clinics. CME credits were offered for their participation. No specific inclusion or exclusion criteria were considered. Two respirologists also participated: one was an 'expert' and the other was an observer. The observer provided support to the facilitator for the initial sessions only.

\section{"I suffer from asthma ${ }^{\complement}$ ": An interactive playing card workshop}

The objectives of the game include the following: to provide relevant content on the main Canadian asthma guidelines recommendations, to experiment with a different and innovative learning format, to stimulate interactivity, to create an atmosphere of healthy competition and to help physicians learn by using an enjoyable game-based method.

The materials needed include: a flip chart to collect information, if needed; a 'patient file' containing one of a number of clinical vignettes, along with the topic number for that vignette (Table 1) (each vignette includes a brief clinical description of a case, the answers to the clinical questions on the 54 playing cards, along with the number of points awarded for each answer or card); a cue sheet for the facilitator on which the topic for each vignette and its corresponding number (from 1 to 10) are marked, along with any relevant clinical information; a deck of 54 playing cards that cover vignettes 1 to 9; and an extra 54 cards for vignette 10 . There are 12 cards per deck in each of the following suits (Table 2): diamonds, which cover patient history and environment; clubs, which cover the patient's current status; spades, which cover evaluation of the patient; and hearts, which cover treatment. There are also four wild cards (one per suit) and three jokers added to each set of 54 cards. The cards are dealt out for each of the four sections of a vignette (evaluation, current status, history and environment, and treatment).

The wild cards can be used at the physician's discretion when requesting information considered relevant to the vignette being played out but that is not in his or her cards. They can only be played when the corresponding suit or phase of the case is in play. The three jokers can be used in the same manner, but during any suit or phase of the case.

TABLE 1

\section{Content of the clinical vignettes}

Topics
$\begin{aligned} & \text { 1. Diagnosis and control of } \\ & \text { asthma }\end{aligned}$
2. Triggers
3. Mild persistent asthma
4. Moderate to severe asthma
5. Exercise-induced asthma
6. Asthma and nocturnal
7. Asthma and nasal polyposis

8. Asthma and beta-blockers

9. Asthma exacerbations
10. Combined therapy
11.* Medication adjustment (1)
12. ${ }^{*}$ Medication adjustment (2)
13. ${ }^{*}$ Severity of asthma versus
noncompliance

14. * Viral-induced asthma

15. * Chronic cough (diagnosis)

\section{Content}

Criteria for the diagnosis and control of asthma

Role of allergens, irritants, smoking and nonenvironmental factors

Management and treatment

Management and treatment

Diagnosis, prevention and treatment

Significance and management of nocturnal asthma

Relationships among these two entities, acetylsalicylic acid and nonsteroidal anti-inflammatory agent intolerance Influence of beta-blockers on asthma Recognition of environmental and other factors involved in asthma exacerbations

How to use combined therapy in asthma

Recommendations on long-term maintenance treatment of asthma

How to assess the minimal medication required to keep asthma under control Importance of assessment of compliance in asthma treatment and consequences of noncompliance

Influence of viral infections on asthma control and management of asthma exacerbations related to respiratory infections

How to distinguish asthma from other entities causing chronic cough

*Additional topic included in the previous vignettes

Points are awarded depending on the appropriateness of the card played. For example, a physician playing a 'heart' calling for the introduction of an inhaled corticosteroid during a vignette that involves a mildly uncontrolled asthma patient who is only on bronchodilators would be given three points, while a physician playing this card during a vignette involving a patient who has a severe acute exacerbation of asthma would collect zero points. If a physician does not have a card he or she considers relevant, he or she can lay down a joker or a wild card, or pass. The physician who lays down a wild card or joker is given the number of points corresponding to the information that is requested on that card, based on the particular vignette being played out, just as for any other card.

Vignette 10 is different from the other nine and specifically deals with the role of combination therapy in asthma in achieving and maintaining asthma control. It requires four additional suits of cards. Case 1 has diamonds, which covers loss of control, and clubs, which covers achievement of control. Case 2 has spades, which covers loss of control, and hearts, which covers regaining of control reached.

A DVD is provided as an aid for the facilitator and the expert. It shows the rules of the game and the content of each section of the workshop. 


\section{TABLE 2}

Content of playing cards for vignettes 1 to 9

\begin{tabular}{|c|c|c|c|}
\hline History and environment (diamonds) & Patient's current status (clubs) & Patient evaluation (spades) & Treatment (hearts) \\
\hline Smoking & Daily activities & Obtaining a report from the & Inhaled corticosteroids \\
\hline \multirow{2}{*}{$\begin{array}{l}\text { Exacerbations during pollen } \\
\text { season }\end{array}$} & Reduced exercise and tolerance & educator at the asthma & Short-acting beta ${ }_{2}$-agonist \\
\hline & Nocturnal awakenings & education centre & Long-acting beta ${ }_{2}$-agonist \\
\hline Contact with pets & Absenteeism (work or school) & Referral to a specialist & Systemic corticosteroids \\
\hline \multirow{3}{*}{$\begin{array}{l}\text { Hospitalizations, emergency } \\
\text { department visits, intubation, } \\
\text { intensive care }\end{array}$} & Exacerbations & Induced sputum analysis & \multirow{3}{*}{$\begin{array}{l}\text { Combination therapy (inhaled } \\
\text { corticosteroid plus long-acting } \\
\text { beta }_{2} \text {-agonist) }\end{array}$} \\
\hline & Current asthma treatment & Ventilation-perfusion scan or blood & \\
\hline & Proper use of drugs and devices & gases & \\
\hline \multirow{2}{*}{$\begin{array}{l}\text { Family history of respiratory } \\
\text { problems }\end{array}$} & Therapeutic compliance & Allergy tests & Leukotriene receptor antagonist \\
\hline & Use of rescue beta ${ }_{2}$-agonists & Exercise test & Concomitant medications \\
\hline History of allergies in the family & Nasal symptoms & Investigation for gastroesophageal & Nonpharmacological measures \\
\hline Associated allergies & Other medications (two cards) & reflux & Environmental measures \\
\hline Relevant comorbidities & & Methacholine provocation test & Treatment of rhinitis \\
\hline Assessment of workplace and & & Spirometry (including reversibility) & Action plan \\
\hline living environments & & Peak flow measures & Referral to an asthma education centre \\
\hline Home heating and environment & & Radiological investigation & \\
\hline Dust mite avoidance measures & & Physical examination & \\
\hline Effect of previous treatment trials & & & \\
\hline
\end{tabular}

\section{The game}

The game is played by three to eight participants. At the beginning of the session, the participants choose the two or three vignettes and corresponding patient files that will be played out, according to the players' needs. Then the game starts. First, one of the participants acts as the 'patient'. He or she takes the patient file and reads the clinical vignette out loud. The deck of 54 cards is then dealt to the physicians so that each physician receives eight cards or more. Each physician then takes a turn laying down a card, explaining very briefly why he or she is playing this particular card. The physician does not choose which cards he or she is dealt and, therefore, he or she does not feel the pressure of making a 'right' or a 'wrong' decision but rather, has an opportunity to talk and learn with each round of cards. The 'patient' then tells the family physician what score he or she received for playing that card. One round is played for each suit in the following order (for vignettes 1 to 9 inclusive): diamonds, clubs, spades, then hearts. After three rounds, covering patient history and environment, current status and evaluation, the 'patient' summarizes all information to this point and asks the physicians whether they require any additional pertinent information before moving on to the fourth and final round, on treatment. Finally, the physicians have a discussion with the 'patient' to arrive at a consensus regarding his or her condition, as well as the therapeutic options that are optimal for this particular patient under the particular circumstances of the vignette that was just played out. This discussion is aided by the expert and the facilitator.

Each player then calculates his or her score, and the winner (the person with the most points) is determined. Next, the winning player or someone else of his or her choosing announces his or her team's (physicians at the same table) consensus. The facilitator presents a wrap-up of the discussions and solicits the expert's comments. The expert gives feedback and presents evidence or expert opinions on the topic that was discussed. And the game starts over again.

\section{Assessment of the method}

Each physician filled out a standardized questionnaire on his or her perception of the game, including its content and properties.
This was largely a qualitative assessment, including some semiquantitative evaluations about specific elements.

\section{PARTICIPATING PHYSICIANS' EVALUATION OF THE METHOD}

Qualitative assessment

Thirty-four physicians were involved in a test of the game during a $1 \mathrm{~h}$ card game workshop and then filled out a questionnaire. Nine physicians then participated in a focus group. All 34 physicians agreed that this method was innovative, stimulating and enjoyable. Although the card game rules did not seem obvious at first, after the initial instructions were provided by the facilitator and the physicians played a first round of cards, the physicians became fully involved in the process. Participants liked the 'play' aspect of the method, and indicated that it facilitated interaction among participants and favoured the participation of all players in an atmosphere of friendly competition.

As expected, each participant had different cards - sometimes with less appropriate content than expected - which made physicians feel less threatened in the presence of their colleagues because everyone knew there was a limited choice of cards or options on which to base his or her decisions. Thus, this stimulated a very open and full discussion of themes relevant to each physician's practice and available resources. It also provided the expert with an opportunity to review the overall optimal management of asthma using the various scenarios. Moreover, practical aspects of day-to-day care of asthma patients were raised, and practice aids were provided to the participants.

\section{Semiquantitative assessment}

The participants either agreed or strongly agreed that the card game was relevant to their practices, that the elements of the game were well explained and that the messages resulting about asthma treatment were clear and practical (Figure 1). With regard to the other characteristics of this method, physicians were asked whether they considered this new method to be appealing and whether it favoured the direction of learning. 


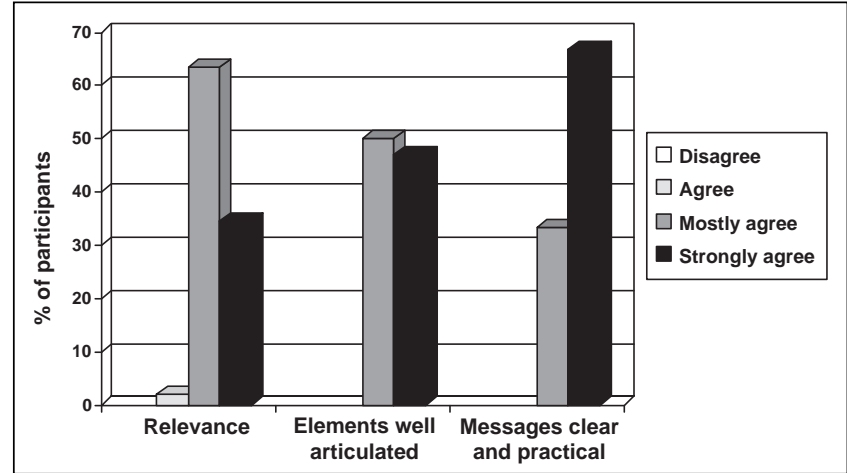

Figure 1) Responses of physicians to a standardized questionnaire about the card game. Most physicians either mostly agreed or strongly agreed that the card game was relevant to their practices, that the elements of the game were well explained and that the messages resulting about asthma treatment were clear and practical

The response to these questions were quite positive as shown in Figure 2. Finally, the participating physicians were asked whether the game would help them to integrate the guideline recommendations mentioned in this session. Many of them believed that the game helped them to apply these recommendations to day-to-day care (Figure 3). Most of the physicians agreed that this would potentially change their practice, although this would have to be assessed in another study looking at the long-term changes in physicians' behaviour and patient outcomes.

\section{DISCUSSION}

We developed a card game-based interactive educational method designed at improving transfer of knowledge about asthma management to primary care physicians. Such play activity, dealing with a specific targeted scientific content based on asthma guidelines recommendations, was well received by participants. They considered this method to be an innovative means of integrating relevant information into current practice. The participants noted that the interaction required by the game, in addition to the discussions with the expert, provided a well-balanced, participatory intervention that favoured active integration of the information. It may engender whole brain learning, which involves a connection between the experiential and the rational (6).

Participants also indicated that they enjoyed the atmosphere of friendly competition and the fact that the card game stimulated learning in a nonthreatening way. They also noted that the method facilitated reflection, interaction and learning, as well as generated useful discussions on how to apply current guideline recommendations into care.

Despite all efforts to produce therapeutic guidelines in the past 20 years, evidence-based recommendations provided in these documents are far from being optimally integrated into current care (2,13-15). Among the various methods proposed to make recommendations from current guidelines relevant and knowledge transfer effective, the most effective were interactive, targeted interventions aimed at helping to integrate these notions into current practice in a way that was relevant to the physicians' background and available resources (4-7).

In this regard, Renzi et al (16) recently evaluated the knowledge of 104 primary care physicians regarding the Canadian asthma consensus guidelines recommendations, as

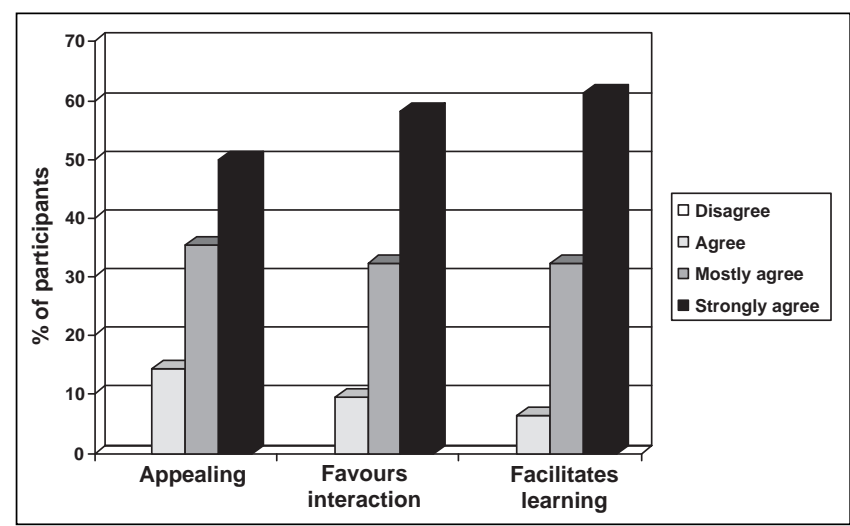

Figure 2) Summary of the physician's assessment of the workshop properties with regard to its conviviality, flexibility, promotion of interaction between participants and facilitation of learning. Most physicians believed that the workshop facilitated conviviality, flexibility, learning and promotion of interaction among participants

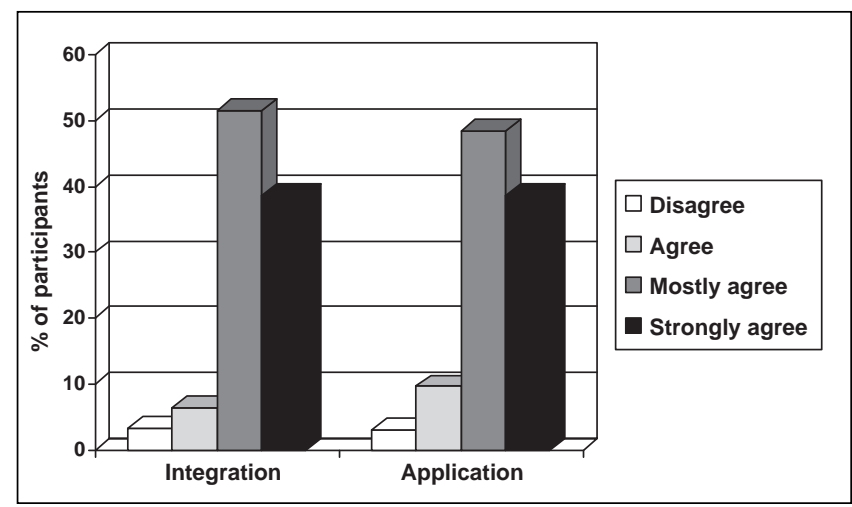

Figure 3) Physician's assessment of the potential influence of the workshop with regard to the facilitation of integration of the information discussed to their practice and how it will help them to apply this information in day-to-day care. Physicians considered that the workshop had a potential to influence the integration of the information discussed into day-to-day care in their practices

well as patient outcomes, before and after introducing physicians to a memory aid in the form of a paper stamp checklist (summarizing criteria and guidelines for assessing asthmatic patient control and therapy). The stamp significantly improved physicians' knowledge of the guidelines when reassessed six months later and reduced emergency room visits, as well as hospitalizations, in patients who were followed for at least one year. These results show the value of the type of method used in helping to translate guidelines into day-to-day care.

Problem-based learning has been advocated as an alternative method for providing CME to small groups of physicians $(6,17,18)$. This method of learning leads to improvements in physicians' behaviour and abilities. In our new model, all participants become involved and can explain their choices in a nonthreatening way and in a nonstressful context. They can compare and discuss the choices of others, as well as consult with an expert.

Foreman (19) suggested that the ideal learning situation is customized to the specific needs of the individual participants, provides immediate feedback, is constructive, motivates 
participants to push themselves to actively learn the material being presented, and builds enduring conceptual structures. We believe that game-based learning should not be restricted to specific populations (such as children) or to methods (such as computer games); rather, it can be extended to innovative forms of medical-education workshops. This may add a component of enjoyable competition that can favour learning while being a low-cost and easily applied concept. Learning involves active participation, analysis, interpretation, problem solving and memory - all processes that apply to this card game-based system (19)

New forms of medical education are always needed. A form that incorporates elements of play and scientific content based on current guidelines is a very dynamic mode of knowledge transfer to general practitioners. It facilitates learning by ensuring active participation, the need for practical analysis of a situation with immediate feedback from experts, and interaction among participants, all in a friendly environment. The method is flexible and can be integrated into other continuing education initiatives. Some physicians may prefer a more conventional mode of education because this model is more demanding, although many may prefer this interactive session because it is better tailored to their needs and their level of knowledge.

It is possible that physicians with a high interest in asthma or new pedagogical methods had attended the session. However, it was interesting to know their opinion about the value of such a tool that could eventually be applied to a larger group of physicians, including some who do not frequently attend this type of activity. In fact, it may be another means to attract more physicians who are less interested about the traditional methods of medical education.

One shortcoming of this method is that it requires all the materials needed and the availability of an expert for each

\section{REFERENCES}

1. Masoli M, Fabian D, Holt S, Beasley R. The global burden of asthma: Executive summary of the GINA Dissemination Committee report. Allergy 2004;59:469-78.

2. Boulet LP. Asthma guidelines. In: Middleton's Allergy: Principles and Practice. WB Saunders, 2004.

3. Partridge MR, Fabbri LM, Chung KF. Delivering effective asthma care - how do we implement asthma guidelines? Eur Respir J 2000;15:235-7.

4. Oxman AD, Thomson MA, Davis DA, Haynes RB. No magic bullets: A systematic review of 102 trials of interventions to improve professional practice. CMAJ 1995;153:1423-31.

5. Ockene JK, Zapka JG. Provider education to promote implementation of clinical practice guidelines. Chest 2000;118(2 Suppl):33S-9S.

6. Borduas F, Carrier R, Drouin D, Deslauriers D, Tremblay G. An interactive workshop: An effective means of integrating the Canadian Cardiovascular Society clinical practice guidelines on congestive heart failure into Canadian family physicians' practice. Can J Cardiol 1998;14:911-6.

7. Boulet LP. How can we translate advances in respiratory diseases into improved care? Can Respir J 2001;8:69-70.

8. O'Leary S, Diepenhorst L, Churley-Strom R, Magrane D. Educational games in an obstetrics and gynecology core curriculum. Am J Obstet Gynecol 2005;193:1848-51.

9. Steinman RA, Blastos MT. A trading-card game teaching about host defence. Med Educ 2002;36:1201-8.

10. Mann BD, Eidelson BM, Fukuchi SG, Nissman SA, Robertson S, Jardines L. The development of an interactive game-based tool for session. Furthermore, some physicians may prefer a more passive way to acquire knowledge, although as mentioned, most participants enjoyed the play. Further evaluation of this method is needed to determine whether the game improves physicians' knowledge, modifies physicians' behaviour and improves their asthma patients' outcomes, particularly when key messages are repeated in additional card-playing or traditional CME sessions. This approach could also be adapted to provide CME on other chronic diseases such as congestive heart failure or diabetes. We hope that the present report will stimulate other initiatives of this type to increase the efficiency of our interventions and to better translate current optimal care recommendations into current practice.

\section{CONCLUSION}

An interactive, educational intervention, integrating play and scientific components to knowledge transfer on asthma guidelines to general practitioners, was well received by participants and stimulated reflection and exchanges on asthma care. This method allows communication of relevant content and stimulates interactivity in a climate of friendly competition. We believe that this interactive method of learning facilitated knowledge transfer and is likely to help improve asthma management.

ACKNOWLEDGEMENTS: We are grateful to Patrice Lemay for his help with data analysis, to all the physicians who participated in the assessment of the workshop and to Dr Michael Marrin, Lyne Bouchard, Danielle Fagnan and Michael Belliveau for their contributions to the development of this educational tool.

FUNDING: This work was supported by an unrestricted educational grant from Merck Frosst Canada Ltd. learning surgical management algorithms via computer. Am J Surg 2002;183:305-8.

11. Lemière C, Bai T, Balter $M$, et al. Adult Asthma Consensus Guidelines Update 2003. Can Respir J 2004;11(Suppl A):9A-18A.

12. Boulet LP, Becker A, Bérubé D, Beveridge R, Ernst P. Canadian Asthma Consensus Report, 1999. Canadian Asthma Consensus Group. CMAJ 1999;161(11 Suppl):S1-61.

13. Jin R, Choi BC, Chan BT, et al. Physician asthma management practices in Canada. Can Respir J 2000;7:456-65.

14. Gibson PG. Implementing evidence-based guidelines. Med J Aust 2001;174:377-8.

15. Boulet LP, Becker A, Bowie D, Hernandez P, McIvor A, Rouleau M. Implementing practice guidelines: A workshop on guidelines dissemination and implementation with a focus on asthma and COPD. Can Respir J 2006;13(Supp A):1A-47A.

16. Renzi PM, Ghezzo H, Goulet S, Dorval E, Thivierge RL. Paper stamp checklist tool enhances asthma guidelines knowledge and implementation by primary care physicians. Can Respir J 2006;13:193-7. (Erratum in 2006;13:279).

17. Maltais P, Goulet F, Borduas F. Educational skills and knowledge needed and problems encountered by continuing medical education providers. J Contin Educ Health Prof 2000;20:91-6.

18. Davis RS, Bukstein DA, Luskin AT, Kailin JA, Goodenow G. Changing physician prescribing patterns through problem-based learning: An interactive, teleconference case-based education program and review of problem-based learning. Ann Allergy Asthma Immunol 2004;93:237-42.

19. Foreman J. Next-generation educational technology versus the lecture. Educause Review 2003;38:13-22. 




The Scientific World Journal


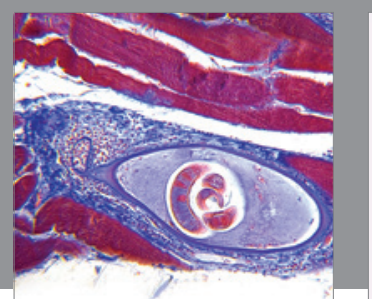

Gastroenterology Research and Practice



\section{Hindawi}

Submit your manuscripts at

http://www.hindawi.com
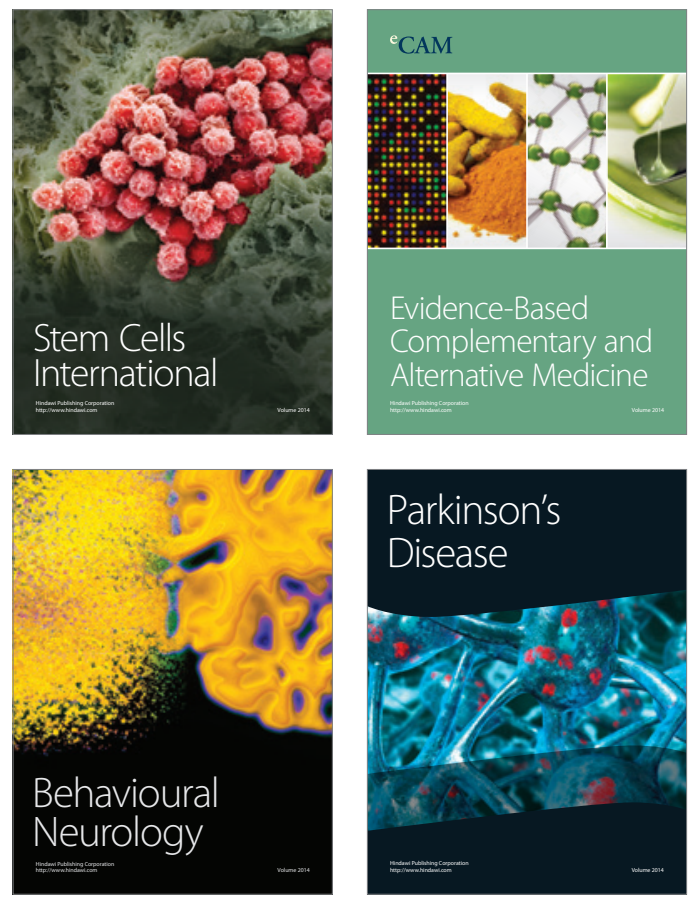
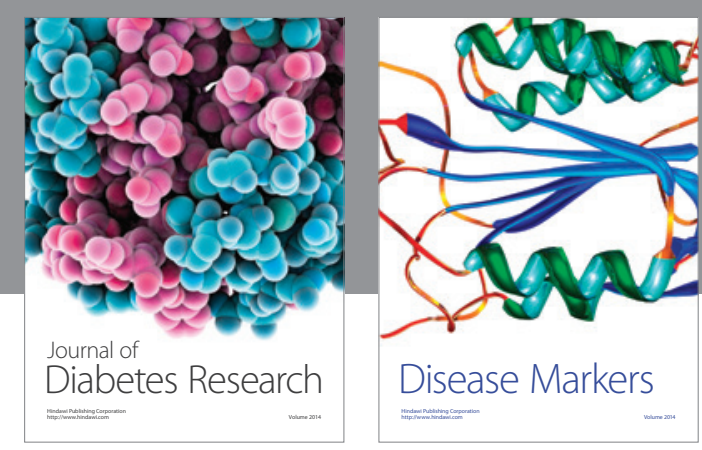

Disease Markers
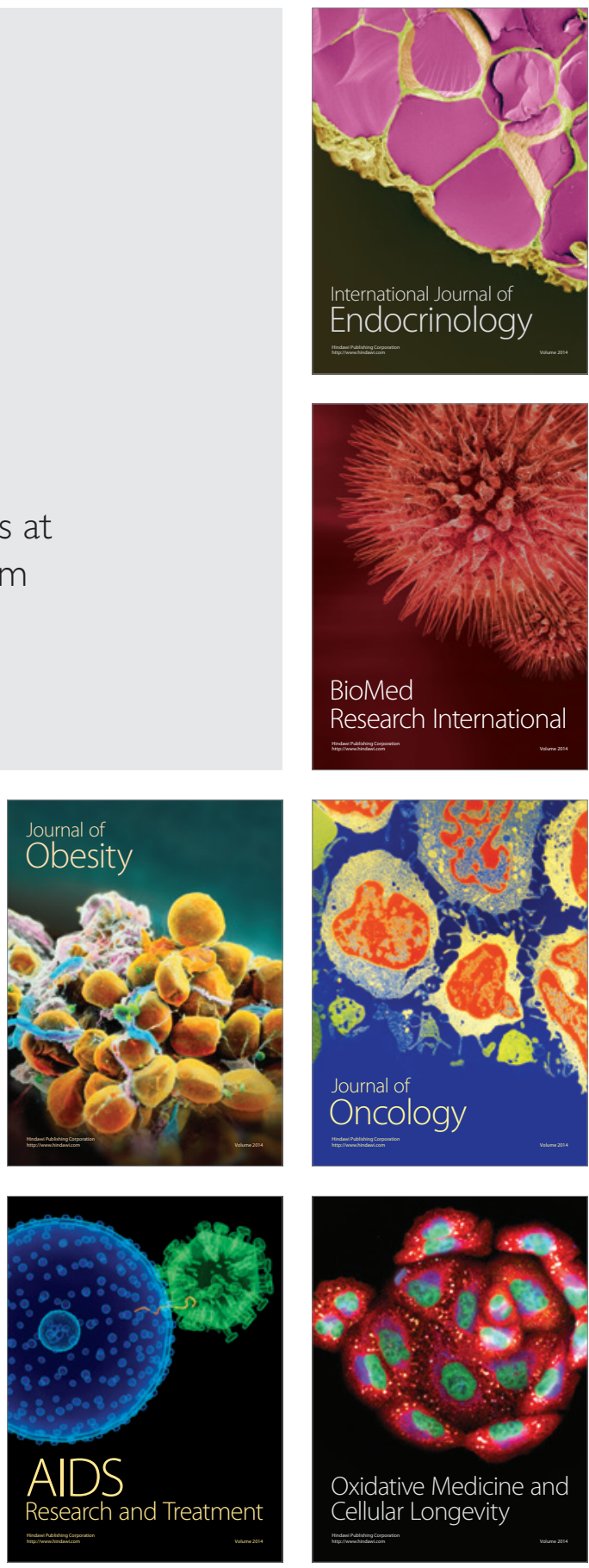